This version is a pre-published one. For citations:

Hadar, L. L. \& Ergas, O. (2018) Cultivating mindfulness through technology in higher education: a Buberian perspective, (ahead of print) AI and Society.

\title{
Cultivating mindfulness through technology in higher education: a Buberian perspective
}

\begin{abstract}
One of the most fundamental concepts within Martin Buber's philosophy concerns two modes of being: I-it, which reflects an egocentric instrumental existence, and I-thou, which reflects dialogical encounter and interrelatedness. At the face of it, technology seems to be the ultimate example of that which engenders and I-it consciousness. Indeed, a recurrent concern in contemporary times suggests that the increase in our technology use is slowly but surely depriving us of meaningful encounters with the other. In this paper we propose that technology can in fact be applied as an antidote to this predicament. To make this point we describe the teaching of mindfulness practice in higher education. We focus particularly on the use of cell phones to cultivate mindful attention as a precondition and characteristic of I-thou relationships. These cell phones, which have somewhat become extensions of our bodies, remind us to become present and hence more likely to acknowledge interrelatedness. Brief excerpts from student projects in these courses will be applied to demonstrate these transitions.
\end{abstract}

Keywords Mindfulness $\cdot$ Technology $\cdot$ Buber $\cdot$ Higher education $\cdot$ Mind-wandering $\cdot$ I-it $\cdot$ Ithou 


\section{Introduction}

A common narrative that has become quite consensual in contemporary times proposes that the growing use of technology is slowly but surely depriving us of a fundamental feature and necessity of human life-connecting with the other. This becomes a substantial problem for the young generation, for a decline in opportunities to engage in human to human interactions means less opportunities to develop social-emotional communication skills. The image of teenagers sitting together, yet each individually absorbed in his or her cell phone, is as pervasive as it is disturbing to those of us who have grown up only 2 or 3 decades ago. This image was eloquently captured in Turkle's (2017) Alone Together, a book that wakes us all up to this gradual takeover of technology over our social engagements. Turkle is hardly alone in these observations. Coming at this theme from the perspective of brain plasticity, Carr (2011) argued that the technologies we create and "put out there", so to speak, become agents in their own right. A reproductive cycle is perpetuated as we practice certain forms of thinking to create technologies, yet once we use these technologies our thinking and behavior are reshaped in turn, based on the structures of these media. Somewhat following McLuhan's (1964) famous aphorism: "the medium is the message”, Carr (2011) proposed the "shallowing hypothesis", namely the increasing use of ultra-brief social media such as texting and tweeting reduces our ability to engage in deep and reflective thought and may lead to moral shallowness. Through such media our brains are habituated into fragmented, quick satisfaction-demanding interactions, which all work against the conditions that forge interrelatedness. A recent research that set out to test this hypothesis studied the texting habits of 149 undergraduate students. Indeed, those who frequently texted or used ultra-brief social media attributed greater importance to "morally shallow" life goals 
(e.g., image and hedonism) than to goals, which are related to morality (Annisette and Lafreniere 2017).

Taken from the perspective of Martin Buber's philosophy, this gradual decline in face-toface human communication and heart-to-heart conversation, seems to bear directly on the conditions that are required for engaging in an I-thou relationship. It is indeed quite hard to imagine how this takeover of technology can have a positive rather than negative effect on the development of such holistic encounters. Though some perhaps harbor the sense that they are now far more 'interconnected' through social networks, as Turkle (2017) argues: “[d]igital connections and the sociable robot may offer the illusion of companionship without the demands of friendship" (p. 2).

Technologies' capacity to habituate us has been framed within an educational context in Postman's (2011) The End of Education. This book was published in the 1990s, hence Postman did not speak of cell phones but rather about the average American who receives much of his education from hours of television watching permeated by commercials. He referred to this as an initiation into the false educational narrative of consumerism, which is perhaps the "epiphany" of an 'I-it' consciousness. It is quite plausible to argue that had Postman lived to our times his critique would have been extended to encompass the contemporary situation described by Turkle (2017) and Carr (2011). In his book, Postman proposed a crucial point that enables us to transition to the core idea of this paper. He argued that the knowledge we need about computers, television, and other important technologies does not concern how to use them as much as it concerns how they use us. Carr's (2011) and Turkle's (2017) books can be framed as doing just that - educating us to realize the power that the very technologies we create have on us. However, once we realize this, the question is what are we to do? Radical and 
idealistic solutions would perhaps seek a romantic or utopian 'return' to other times, doing away completely with cell phones and internet usage. More pragmatic solutions, however, would propose less radical solutions, such as a 'cell phone-free Monday' or avoiding emailing while with our kids. This paper follows some who have been developing pragmatic solutions that stem from the question: how can we use technology as an antidote to the predicament that technology itself creates?

A central context within which such solutions have begun to emerge stems from the locus around which the entire predicament revolves - the faculty of attention. Both Carr (2011) and Turkle (2017) point to this. Carr's (2011) account speaks directly to the way in which instant messages cater to the brain's natural patterns of distractedness and hence risk exacerbating fragmented thinking. Turkle's (2017) book similarly revolves around how technological devices shape the ways in which we attend to each other as well as to virtual realities (e.g., a Tamaguchi, a robot). These contemporary contexts can be framed more broadly within claims made by psychologists such as James (1981) and later Csikszentmihalyi (1996). Both pointed to the fact that our realities are shaped by what we attend to and by how we attend to it. In fact, an often-cited quote from James associates education directly with cultivating attention: "The faculty of bringing back a wandering attention over and over again, is the very root of judgement, character and will... an education that should improve this faculty would be the education par excelance." (James 1981, p. 401). In as much as technology brings forth remarkable advances and improvements into our lives it seems to have become the agent that determines what we attend to and how we attend to it. When framed this way, it seems like we are in need of pedagogies through which we can recover our agency over attention from the hands of the technologies we create. It is within this context of recovering our agency over 
attention that the context of mindfulness in education enters here (Ergas 2017). Mindfulness practice has been defined by Kabat-Zinn (1994) as a practice of "paying attention in a particular way, in the present and non-judgmentally" (p. 4). A common formal mindfulness practice as currently introduced across various educational settings (Schonert-Reichl and Roeser 2016) is a meditative practice in which one brings his or her attention to the sensations of the breath (e.g., in the abdomen, nostrils). Whenever one notes that attention had wandered to another object (e.g., a thought, external sound), one brings attention back to the breath without reprimanding oneself for losing concentration. In the past three decades, over 3000 studies concerning the effects of mindfulness on various aspects of mental and physical health, cognitive functions have been published (Black et at. 2017). Of particular interest here are those studies that specifically concern how mindfulness affects our attentional habits. With some exceptions, most studies found that mindfulness practice implemented in diverse ways leads to improvements in sustained attention (MacLean et al. 2010; Semple 2010), orienting attention (Jha et al. 2007), attention regulation (Tang et al. 2007; Wenk-Sormaz 2005), and selective attention (Jensen et al. 2012), as well as in changes in neural activity and underlying neural architecture associated with attention networks (Malinowski 2013; Moore et al. 2012).

When one analyzes the pedagogical foundations of mindfulness practice, one can see that it is underpinned by ingredients that can all be viewed as antidotes to the fragmented, distracted and careless mode of attention that technology is accused of engendering: contrasting the fast paced world of tweeting and texting, mindfulness is about slowing down. Opposing the extravagant images on our screens that lure attention, mindfulness positions the breath as a rather 
monotonous stimulus for the mind to focus on. Rather than have our attention focus passively on what is outside us, mindfulness asks us to attend inwardly to our minds and bodies. Rather than a fragmented, frenzied and scattered attention that runs after stimuli that catches one's interest, mindfulness encourages long periods of sustained attention. For these very reasons, for many of us, mindfulness practice is hard to commit to. One who attempts this practice for the first time will quickly reaffirm Carr's (2011) observation about the brain's natural tendency toward distractedness. One might manage to position attention over the breath very briefly, yet only to discover oneself lost in thoughts and forgetting the intention to practice at all. Nevertheless, as the research above suggests, those who commit to such practice cultivate better control over their attention. Such control means being better able to decide what to attend to, how to attend to it, and when to attend to it, i.e., it means recovering our agency over the faculty of mind that determines their quality (Csikszentmihalyi 1996; Ergas 2017; James 1981).

\section{Mindfulness, mind-wandering, I-it and I-thou}

While mindfulness is known as a practice it is also known as a state of mind which is cultivated by this practice. Contemporary literature, especially scientific studies of the effects of mindfulness practice, often highlight the practice and its outcomes without dwelling on the nature of this state of mind. Yet, it is this state of mind, and the state of mind wandering and mindlessness that are its opposites, which are particularly crucial for explaining the connection of this paper to Buber's philosophy. Following the above and leading to the core context of this paper, we argue that Bubber's "twofold attitudes" (Buber 1970) - I-it and Ithou-lend themselves to two modes of attending to the world. I-it is associated with a mode of instrumental attention that disintegrates and reifies the world based on the way we perceive it as 
serving or working against our interests. That which we experience based on this mode is treated wittingly or unwittingly as a means to another end and our entire experience is thus framed based on our conception of whether it is for us or against us (Buber 1970). Conversely, Ithou is associated with a holistic mode of attention that captures the whole of being of the self and the other (which can be nature as well) coevally (Buber 1970). This mode of attention is one that connotes with being present and open to receive experience as it unfolds and without preconditions. "the man living in responsibility" according to Buber (1965) faces "the hour which approaches him, the biographical and historical hour; just as it is, in its whole world content and apparently senseless contradiction, without weakening the impact of otherness in it," (p. 65-66). Buber's co-existentialist dialogical philosophy is an attempt to articulate these two modes from the perspective of the kind of encounter that each creates. The perspective we offer in this paper turns to explore the mind of s/he who attends to the world in these ways (Ergas 2017) for as Buber claimed: "Concentrated into a unity a human being can proceed into his encounter" (Buber 1970, p. 134). In fact, Buber speaks of two kinds of unity—an inner unity and a relational unity, the former being a precondition for the latter: "with it, he decides, in his innermost being, if this means a breathing space, or the sufficient end of his way" (Buber 1970, p. 134). 'Innermost being' and 'breathing-space' seem to point toward mindfulness either literally or metaphorically as Buber also claimed that " $[\mathrm{I}] \mathrm{n}$ order to be able to go out to the other, you must have the starting place, you must be with yourself' (Buber 1965, p. 21). We argue then that the cultivation of mindfulness aims at this inner unity and hence implies the cultivation of conditions that are conducive to a transition from an I-it instrumental state of mind to an Ithou state of mind. Conversely, the state of mind-wandering, which has been considered 
as antithetical to mindfulness, is an expression of $\mathrm{I}-\mathrm{it}$. We describe these two states in the following.

Mindfulness as a state of mind is interpreted diversely and sometimes in highly complex and intricate ways. It has been characterized based on qualities such as being awake and present within a situation without stamping it with our wish to make it suit our egocentric desires (Olendzki 2011). Such mode of attention is quite remote from what we usually experience in day-to-day life. Our common experience is one in which we are mostly concerned with making things suit how we want them to be (e.g., completing chores, getting somewhere, rushing our kids to school). Mindfulness suggests an inner letting go and letting be (Yates et al. 2015). It is a state of mind in which we do not force ourselves over the situation; rather, we become attentive and open and hence, in Buberian terms a relationship with 'Thou' automatically becomes possible. The most fundamental precondition for an I-thou encounter is that we will be present here and now, and not harbor the wish for the current moment to be different than what it is. If we experience an intention of wanting to "get something over with" or "wanting it to be other than what it is" then such intention cannot but yield an I-it attitude for this moment is not valued in and of itself.

On the one hand, mindfulness as this open mode of attention is not mysterious at all for those experienced in mindfulness practice. On the other hand, our day-to-day consciousness is very distant from it, and it is this very day-to-day consciousness that we first encounter when we begin practicing mindfulness. When practicing mindfulness most of us will habitually express an I-it mode of attention. Rather than attend to our breath, and stay there thus expressing that it is actually good enough to simply be, our minds will begin wandering to plans we have for the future, and memories from our past. 
Mind-wandering has become a substantial field of research and has been conceptualized as antithetical to mindfulness (Mrazek et al. 2012). It is the state of doing one thing yet unwittingly thinking of something else. We do not choose to do this; it is rather a feature of our busy minds, which becomes explicit when we attempt to cultivate mindfulness. As such mindwandering has been conceptualized as reflecting the mind's poor ability to remain grounded in embodied and present experience. These constant projections of our own mind to future and past endeavors can be framed as an expression of an I-it mode of attention that is enacted within us without our directly inviting this situation (Ergas and Berkovich-Ohana 2017). Mindfulness practice is an attempt to bring our mind to the present sensations of our body and hence create the conditions for an I-Thou encounter. The more we become aware of different kinds of attending, and the more we cultivate the internal ability to change how we attend, the greater the chances of enjoying the merits of an I-thou engagement with others.

As Czubaroff (2000) interprets Buber's I and Thou "In dialogue we overcome our separateness, for everything 'permeates everything else,' and we encounter the other's being or actuality in the timeless present moment" (p. 172). In fact, studies now demonstrate that increased mind-wandering is associated with reduced compassion for others (Jazaieri et al. 2016). This makes sense if we consider that the more we are absorbed in our own problems as we wander in our minds, the less resources are left for our attention to actually see the suffering of others.

\section{Education, mindfulness and technology}

Some scholars have been seeking ways to recruit technology, accused of leading us toward an I-it existence, to in fact reverse this orientation and cater to our yearning for a more 
centered, agentic and meaningful life. Technology, in this sense can be seen as a persuasive media, a system that provides a compelling experience that can help people change their attitudes or behaviors (Fogg 2003; Vidyarthi and Riecke 2014). If persuasive media could offer an experience which influences people's lives, it could potentially trigger long-term changes in behavior and routines towards a more meaningful life. Within the field of mindfulness, headspace is one of the most well-known developments with its app, which provides a virtual platform for teaching mindfulness. In a study from 2015 it was found that participants who had little or no prior experience with mindfulness practice and trained in mindfulness based on this app for 3 weeks of daily 12-min sessions showed significantly higher levels of empathic behavior (Lim et al. 2015). Another case of this strategy comes from neuroscientist Judson Brewer's lab, who has been developing mindful apps, which are specifically designed to helping smokers quit smoking through mindfulness practices that make them more aware of their habit (Brewer 2017).

This pragmatic approach has also been applied in some university courses. One recent account is Levy's (2016) teaching of "Information and Contemplation"- a course at the information school at the University of Washington. Documented in his recent Mindful Tech this course takes students on a journey into mindfulness practice and its application toward exploring habits of technology use. Through a series of mindfulness exercises designed particularly around texting, emailing, blogging, Facebooking and other, students re-evaluate how their identities and daily lives are constructed through technology use. Broadly, the thesis suggested by Levy (2016) is that technology is not necessarily a domain in our lives that should inevitably take us down the road of entrenchment in an I-it existence. We can in fact engage differently 
with ourselves, through mindful attention, while interacting with technology and transform this into a practice of cultivating more aware social engagements and possibly I-thou encounters. Following this orientation, we turn to elaborate on a teacher education course taught in a college in Israel focused around mindfulness. We describe the course broadly, and then focus specifically on an experiment introduced in it, which relies on cell phones as real-time reminders, which promote mindfulness and a movement from I-it to I-thou.

\section{Mindfulness and social-emotional learning course}

"Mindfulness and social-emotional learning" is an advanced one semester course (14 meetings) for Master's degree students studying to become high school teachers. It has been running for 5 years with each cohort including approximately 35 students. The course focuses on the theory and practice of mindfulness and their relation to the field of social-emotional learning (SchonertReichl and Roeser 2016). All lessons include at least 10 min of formal mindfulness practice, followed by approximately 15 min of discussion in which we inquire into the individual experiences that students encounter during practice, and further instructions on how to practice are offered. The rest of each lesson is focused on the origins and the science of mindfulness. The overall framing of the course is one of self-exploration and experimentation. Mindfulness is offered as a way to know ourselves better.

The main requirement of the course is a daily 15 -min home practice, documented in a personal journal. In their journal students write how they feel before the practice, what they experienced after the practice, and any personal thoughts and insights they wish to document. This journal becomes a daily pre-/post-documentation of this experiment and serves as the database for students' autoethnographical final projects at the end of the course. Students select 
this course out of a number of other possible courses hence most are motivated to study mindfulness. Nevertheless, the commitment to a daily practice has always been a problematic issue that runs as a thread throughout the course, in all of the years of its existence. On the one hand, students indeed wish to practice, and the scientific evidence of mindfulness's salutary effect that are presented in some of the sessions serve as somewhat of an incentive to do so. On the other hand, at the beginning of the course hardly any of the students manage to comply with the daily practice requirement. A well-known negative reproductive cycle emerges here since little practice yields little results, which in turn reduces motivation to practice (Bickmore et al. 2007). In the following, we focus on a particular part of the course, which directly relates to the role of technology use in mobilizing students from I-it to I-thou modes of attention.

\section{The mind-wandering exercise}

The problem of finding motivation to practice is one with which many struggle and for some years we sought pedagogical ways by which to overcome this predicament in this course. Approximately 5 years ago a solution came from an unexpected place - a seminal study published in Science. In this study, Killingsworth and Gilbert (2010) sought to test the thesis offered by many wisdom traditions, namely that being here and now, being present and mindful to what we are doing, brings happiness. 2250 adults were provided with an iPhone app that randomly prompted them ten times during the day. When prompted they were to answer these three questions: (1) How do you feel? (rate between 0 and 100). (2) What are you doing right now? (e.g., reading, driving, speaking on the phone). (3) Are you thinking about what you are doing? (Four options: (a) yes, (b) no, thinking about something pleasant, (c) no, thinking about something neutral, (d) no, thinking about something negative). 500,000 samples were collected 
from the subjects' responses and the title of the paper declares the results unequivocally: $a$ wandering mind is an unhappy mind. $46.9 \%$ of the samples indicated mind-wandering, and it turned out that neutral or positive thoughts while wandering do not affect our level of happiness, whereas negative thoughts tend to depress us. While Killingsworth and Gilbert's (2010) study is framed as a scientific experiment, we thought that in this course it can be used as a pedagogy that might serve two aims. First, formal mindfulness practice can feel somewhat removed from life and unnatural to some students. This experiment brings mindfulness into daily living. Here we use the common instrumental cell phone as a way to awaken us to our attentional habits during our daily endeavors. The cell phones present a stimulus which can promote the students to perform the desired behavior (Bickmore et al. 2007). Second, perhaps if students realized how much wandering preoccupies their waking hours, and how much it affects them, they might become more motivated to practice mindfulness. Given these considerations, on the fourth session of the course we engage in a week-long experiment. In our case, students ask a friend to set their cell phones to prompt them at five random times during their day. For 6 days they $\log 30$ samples and then they are to hand in a 200 word reflection on the process. Since this mindwandering experiment was incorporated 5 years ago, as of now 183 students participated in it, as each year one cohort of approximately 35 students have enrolled for the course and handed in these reflections. In the following we bring a sample of these reflections. We frame them based on three categories that aim to demonstrate the ways in which the use of cell phones makes students more aware of mind-wandering as an I-it and less desirable attitude, and present mindedness as one, which is more desirable. 


\section{Student reflections}

Student reflections show how the mind-wandering cell phone experiment enhanced their attention on three levels: for some the experiment opened their minds to the awareness that most of the time they are living in the I-it state of mind, and that this state of mind is undesirable. For another group of students the experiment marked a turning point in their commitment to practice mindfulness. For a third group of students the exercise cultivates proneness to the I-thou mindset.

\section{Awareness of I-it as an undesirable state of mind}

For many students the mind-wandering exercise and the use of the cell phone reminder promoted insights in regard to how their mind expresses I-it attitudes. In many cases they acknowledge this as an undesirable mode. The following two excerpts begin to demonstrate students' startling realization - that their minds seem to naturally work against their attempt to be present. TS (2014 cohort): "The most fundamental thing that I have learned about myself as a person in this exercise is how much my ability to focus my attention is nil [italic in original]. My mind, that I had thought of as the essence of my existence is not in my control. It had exposed itself as elusive and has a mind of its own. From an existential perspective this is a heavy conclusion, and it bothered me a lot."

J (2014 cohort): "Based on this experiment I realized how difficult it is for me to control my thinking. Throughout the experiment I found myself not even knowing exactly what I was thinking. This really worried me, because I realized how unaware I am of this thing called "I". I tried to track my thoughts and see how one thought give birth to the next, but even when I tried to really observe the thoughts after a short while I would get sucked into them, without managing 
to observe them from the 'outside'. This means that I don't have control over my life. If I can't control even my own thoughts, is there and I at all? It's like my brain resists me. How can I live in the present if I can't sustain it in my mind?"

The next excerpt reveals this mode of attention to reflect the instrumentalism of I-it. H's (2015 cohort): "I have learned that I am not living in the present...in my thoughts I usually chase after future events, preparing assignments, meeting requirements, going places, submitting hand-ins. I am busy in metaphysical time thoughts (past and future). When looking at the brain I see my strange and bouncy conduct. Its an obsessive preoccupation with the future, and its planning, in things that have already happened in the past and my bouncing from one thing to the other. The mind wandering exercise made me aware of this state of mind I am in and made it even clearer. The observation led me to understand that I cannot let myself follow the thoughts because they change so frequently, they are attracted to stimuli and powerful emotions. I have learned that I am better off keeping away from them and finding some more stable personal foundation."

H literally discusses presence and how her own mind's habitual wandering draws her away from it. She characterizes her mind-wandering as a constant preoccupation with achieving various instrumental aims - an expression of an I-it attitude. This is experienced as an undesirable attitude. While not necessarily a comfortable realization, the experiment is here described as a catalyst that brings forth a strategic decision. Whether she can actually follow her own strategy is questionable, yet the realization itself seems to be important in its own right. N's (2016 cohort) experience in the following reveals the consequences of such realization within a social situation: 
"During the week of the mind-wandering exercise, the phone buzz caught me when I was with my friends at the mall. When I answered the third question, I marked that I was not present and thinking an unpleasant thought. I noticed that I wandered to a thought about a hand-in that I had to prepare for that week. I couldn’t enjoy being with my friends. I was preoccupied with other things and only wanted to go back home."

Here we see how the realization of mind-wandering as an I-it mode of attention affects N's ability to engage in present moment relationships with others. Mind-wandering in this case shapes her experience with her friend. From her words we learn that she would have expected to enjoy her time with her friends. However, in complete opposition to this, given her mind's positioning her future projects at the forefront of her experience, she experiences being with her friends as getting in the way of completing other chores. We can see how our minds can thus pull us toward I-it, and hinder the precondition of presence that undergirds I-thou. Importantly, it is the cell phone experiment, which brings forth this uncomfortable realization.

\section{Technology as an enhancer of a turning point}

Over the years, the wandering mind cell phone exercise was mentioned by students not only as important, but also as a turning point in the course that substantially enhanced their commitment to practice mindfulness. S (2016 cohort), for example, writes:

"The point at which I found that something had begun to change in the way I experience the course came with the mind-wandering experiment...though throughout the course the journal was significant as a tool for sustaining some kind of practice; still, something in this experiment was more conducive to my ability to analyze my experience...After the exercise I started to 
draw conclusions, think out loud and construct a new progression. I tried to understand what created such an antagonism toward the formal mindfulness practice in me and to create a different disposition toward it."

This experience of disconnection from the practice appears frequently. For those unaccustomed to mindfulness it indeed feels very different than our ordinary life. R (2016 cohort) thus wrote in her journal before the experiment: "maybe I should quit, I have nothing to journal about, I don't know what to feel, and I am distressed”. She kept on hoping that at some point she would get something from this course. Nicely expressing this turning point she wrote in her project: "Then, 'bang': the mind-wandering experiment arrived, or an exercise in awakening as I refer to it. From the log we were asked to fill I received empirical proof of what I had already known — that I wander a lot and I view this as a negative experience."

In M's (2016 cohort) project, a more elaborate description is presented, beginning with disconnection, moving on to the experiment as a turning point (here literally articulated as such) and then a stronger commitment to the practice: "In the beginning of the course I wasn't interested much in the formal practice. Maybe it's because I know myself as one who has never been connected to yoga and meditation. Practicing throughout the week was very difficult for me. I felt complete boredom. I wrote in my journal: “this practice is so boring. I just can't see what people find in it"...I also noticed a lot of antsy-ness throughout my body: "my entire body is angry right now, isn't this supposed to calm me down or something of the sort?"...the mere thought that I'm not doing all those things I'm supposed to be doing makes me want to stop. This was the gist of things until the mind-wandering experiment exercise was given. There I started to realize that my journaling was all focused on the future and on regretting all kinds of things I did and not on what I was experiencing during the practice...this experiment was a significant 
turning point in the course for me. It made me become more accurate during the practice and challenge myself constantly."

\section{Contemplations of presence and cultivation of I-thou}

For some students, the mind-wandering exercise and the use of the cell phone reminder promoted insights in regard to how their minds express I-it attitudes. Others, like A and T, as exemplified here, were led to interesting insights into their experience of presence in general: A (2014 cohort): "Suddenly I understood mind-wandering. I realized just how unaware I am of what is going on...it connected with our discussion of "a wandering mind is an unhappy mind". I had certainly known that I am unhappy, but suddenly I found a possible reason...I found myself even outside the formal practice, "catching myself" wandering, and I sensed that my awareness to this has started to extend to other parts in my life."

T (2014 cohort): "During the mind-wandering experiment I realized how non-present I am. I am busy with the future and the past but almost never with the present. Something in this realization really struck me. I suddenly understood that all I'm doing is worrying about a time I can never

actually live in. I recalled the Sesame Street episode in which one of the puppets wants to get to a place called 'there' but always finds himself 'here'. Suddenly, I realized why it was so hard for me to practice. I resolved to remain present."

While A shows proneness to I-thou by discussing how he started to catch himself wandering in situations other than the formal practice, T's proneness to I-thou is apparent in her understanding why it was hard for her to practice before this exercise, and in her decision to remain present. L's and M's excerpts brought hereafter express similar insights into presence; however, they also relate them to a growing sense of well-being: 
L (2016 cohort): "From analyzing the experiment I found that there is a clear connection between wandering and my sense of well-being. The optimal state for me is when my mind is clear and I'm focused on the present."

M (2015 cohort): "The experiment emphasized something that troubles me a lot—my inability to focus on one thing without distraction. Often others comment on this about me so it bothers me...Based on this experiment I observed that during the few times in which my mind was present I felt awake, interested and enjoyed the situation. "

In accordance with Killingsworth and Gilbert's (2010) findings, both L and M associate a state of presence with a sense of well-being, whereas lack of presence and wandering are viewed unfulfilling. Importantly, M's excerpt demonstrates that the world around us can alert us to our not being present. However, we ourselves need to be attentive to these alerts. It appears that the experiment made by M seems to both become more attentive to this, and develops a more nuanced understanding of what it feels like for him to be present. Very much following Plato's paradox of learning in the Meno, i.e., how can I know that I know something that I have not known before, we argue that as long as we do not know what being present feels like from our own experience, we will find it hard to (re)establish such state based on the agency of attention. M seems to express the beginning of such process.

\section{Conclusion}

The various excerpts we brought from students' reflections on the mind-wandering experiment offer a significant lesson. Our cell phones—accused of exacerbating our minds' instrumental I-it tendencies - can in fact be skillfully used to counteract this very effect. It is in fact by re-framing our relationship with these tools that we can transform these 'classic' I-it 
enhancers to tools that might make us more aware, more mindful and present, and hence more likely to experience I-Thou moments. It takes looking with a fresh gaze at technology in general to remind us that technology is broadly, what humans invent to improve their lives. It is, however, not the domain of technology to determine what counts as 'improvement', though in this domain technology's role is sometime confused, as people tend to view it as a good in its own right. Consider, for example, the pace in which people upgrade iPhones, which to some degree simply do the very same thing, only faster. As they do it faster they take us more quickly away from the kind of experiences that Buber viewed as loftier, and as it seems, students too, perceive as more desirable. Following Postman (2011), it is the task of education to determine what improvement means, and re-situate it within I-Thou. Indeed as he suggests, in this case, education can be about warding off technology's grip over the human mind, which is naturally inclined to escape the present. I-Thou a la Buber, is not a state that can be sustained once and for all; rather, it requires constant vigilance (Czubaroff 2000, p. 172). Such vigilance, as it appears, does not characterize our stressed and wandering minds. Along with formal practices such as mindfulness, our technologies can be used to cultivate that vigilance rather than to cater to our lesser qualities, which eventually determine how we shall engage with each other. We end this paper, however, with a reflection that brings more complexity to the situation and provides another angle on technology, mindfulness, and Buberian education.

TS (2014 cohort): "We discussed mind wandering again...I don't know what to think of it any more. I chose to accept it in a way that doesn't fit with the way we discussed things in the classroom. I think mindwandering is unavoidable... Like any other human trait it has disadvantages and advantages to it. It's natural. If a person doesn't wander from time to time, is he a person or a robot? It's not something we should seek to completely eradicate." 
TS expresses an ambivalence that is sometimes found in these projects, which appears pervasively in the research of this field (Ergas and Berkovich-Ohana 2017). Some students experience wandering as a place of freedom rather than a place of undesirable compulsive thinking. TS in fact proposes that wandering is the very place that sets us apart from the technologies (such as robots) we create. He associates mindfulness with an over-controlled mode

of being that becomes unnatural. Indeed, this is not about the eradication of mind-wandering, but rather about reminding ourselves of Buber's words: "Without 'It' a human being cannot live; but he who lives only with it is not human" (Buber 1970, p. 85).

\section{References}

Annisette LE, Lafreniere KD (2017) Social media, texting, and personality: a test of the shallowing hypothesis. Personality Individ Differ 115:154-158

Bickmore T, Mauer D, Crespo F, Brown T (2007) Persuasion, task interruption and health regimen adherence. In: Paper presented at the International Conference on Persuasive Technology, pp 1-11.

Black DS et al (2017) Research publications on mindfulness. http://www.mindfulexperience.org/mindfo.php. Accessed Nov 2017

Brewer J (2017) The craving mind: from cigarettes to smartphones to love? Why we get hooked and how we can break bad habits. Yale University Press, New Haven

Buber M (1965) Between man and man. (Smith RG, trans.). Routledge \& Kegan Paul, London

Buber M (1970) I and Thou. (W. Kaufmann, trans.). Charles Scribner's, New York

Carr N (2011) The shallows: what the Internet is doing to our brains. WW Norton \& Company, New York 
Csikszentmihalyi M (1996) Flow and the psychology of discovery and invention. Harper Collins New York

Czubaroff J (2000) Dialogical rhetoric: an application of Martin Buber's philosophy of dialogue. Q J Speech 86(2):168-189

Ergas O (2017). Reconstructing 'education' through mindful attention: positioning the mind at the center of curriculum and pedagogy. Palgrave Macmillan, Basingstoke

Ergas O, Berkovich-Ohana A (2017) The self-generative mind in education: review and future possibilities. Mind Brain Educ11(4):213-226

Fogg BJ (2003) Persuasive technology: USING computers to change what we think and do (Interactive teachologies). Morgan Kaufmann Publishers, San Francisco

James W (1981) The principles of psychology. Harvard University Press, Cambridge (1890)

Jazaieri H, Lee IA, McGonigal K, Jinpa T, Doty JR, Gross JJ, Goldin PR (2016) A wandering mind is a less caring mind: daily experience sampling during compassion meditation training. J Posit Psychol 11(1):37-50

Jensen CG, Vangkilde S, Frokjaer V, Hasselbalch SG (2012) Mindfulness training affects attention—or is it attentional effort? J Exp Psychol Gen 141(1):106-123

Jha AP, Krompinger J, Baime MJ (2007) Mindfulness training modifies subsystems of attention. Cognit Affect Behav Neurosci 7(2):109-119

Kabat-Zinn J (1994) Wherever you go, there you are: mindfulness meditation in everyday life. Hyperion, New York

Killingsworth MA, Gilbert DT (2010) A wandering mind is an unhappy mind. Science 330(6006):932-932 
Levy DM (2016) Mindful tech: how to bring balance to our digital lives. Yale University Press, New Haven

Lim D, Condon P, DeSteno D (2015). Mindfulness and compassion: an examination of mechanism and scalability. PloS One 10(2):e0118221

MacLean KA, Ferrer E, Aichele SR, Bridwell DA, Zanesco AP, Jacobs TL et al (2010) Intensive meditation training improves perceptual discrimination and sustained attention. Psychol Sci 21(6):829-839

Malinowski P (2013) Neural mechanisms of attentional control in mindfulness meditation. Front Neurosci 7:1-11

McLuhan M (1964) Understanding media: The extensions of man. The MIT Press, Cambridge

Moore A, Gruber T, Derose J, Malinowski P (2012) Regular, brief mindfulness meditation practice improves electrophysiological markers of attentional control. Front Hum Neurosci 6:1-15

Mrazek MD, Smallwood J, Schooler JW (2012) Mindfulness and mindwandering: finding convergence through opposing constructs. Emotion 12:442-448

Olendzki A (2011) The construction of mindfulness. Contemp Buddh 12(1):55-70

Postman N (2011) The end of education: redefining the value of school. Vintage books, New York

Schonert-Reichl KA, Roeser RW (eds) (2016) Handbook of mindfulness in education: integrating theory and research into practice. Springer, Berlin

Semple RJ (2010) Does mindfulness meditation enhance attention? A randomized controlled trial. Mindfulness 1(2):121-130 
Tang Y-Y, Ma Y, Wang J, Fan Y, Feng S, Lu Q et al (2007) Short-term meditation training improves attention and self-regulation. Proc Natl Acad Sci USA 104(43):17152-17156

Turkle S (2017) Alone together: why we expect more from technology and less from each other. Hachette, UK

Vidyarthi J, Riecke BE (2014) Interactively mediating experiences of mindfulness meditation. Int J Hum Comput Stud 72(8):674-688

Wenk-Sormaz H (2005) Meditation can reduce habitual responding. Adv Mind-Body Med 21(34):33-49

Yates J, Immergut M, Graves J (2015) The mind illuminated. Dharma Treasure Press, Arizona 